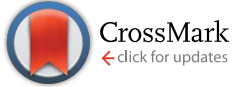

Cite this: RSC Adv., 2017, 7, 5790

\title{
Highly effective removal of malachite green from aqueous solution by hydrochar derived from phycocyanin-extracted algal bloom residues through hydrothermal carbonization
}

\begin{abstract}
Hong Zhang, ${ }^{\text {ab }}$ Fayu Zhang ${ }^{d}$ and Qing Huang*abc
Huge volumes of harmful algal bloom residues ( $A B R$ ) are collected during emergency treatment of cyanobacteria blooms, and phycocyanin-extracted algal bloom residues (PE-ABR) are produced after extraction of phycocyanin from ABR. To utilize them in a more efficient way, we propose a new approach to prepare hydrochars from PE-ABR through hydrothermal carbonization (HTC). The physical characters of as-prepared hydrochars were analyzed by SEM, FTIR and Raman spectroscopy. The PEABR hydrochar showed remarkable adsorption capability for removal malachite green (MG), with the maximum adsorption capacity of PE-ABR hydrochar for MG was $89.05 \mathrm{mg} \mathrm{g}^{-1}$. The adsorption equilibrium is consistent with Langmuir's model, and the adsorption kinetics follows the pseudo-secondorder equation. Therefore, this work have demonstrated that harmful ABR can be utilized not only as a potential material for production of phycocyanin, but also an excellent source for hydrochar for removal dyes in contaminated wastewater with high adsorption efficiency.
\end{abstract}

Received 5th December 2016

Accepted 5th January 2017

DOI: $10.1039 / c 6 r a 27782 a$

www.rsc.org/advances
States, China, Canada, and the European Union, ${ }^{5}$ and the environmental quality standard limit of concentration of MG in water is set in the range of $0.5-100 \mu \mathrm{g} \mathrm{L^{-1 }} .^{6}$ To remove dyes in dye-contaminated wastewater with high concentration, the conventional methods are employed which include aerobic and anaerobic microbial remediation, chemical coagulation, reverse osmosis, oxidation, ion exchange, membrane filtration and electrochemical approaches. But generally, these methods either require high cost of exploitation or are incapable of treating large volumes of effluent., ${ }^{2,6}$

Alternatively, it is also effective to employ the adsorption method by using solid as adsorbents in treatment of dyecontaminated wastewater. In application of this method, the most widely used adsorbent is activated carbon (AC). However, up to now, production of commercial activated carbon is still an expensive process. Therefore, it is of immense interest to search for a more cost-effective production process of AC materials. ${ }^{7}$ In this regard, people have tried the methods of pyrolysis of biomasses for production of char material, such as the dry pyrolysis and wet pyrolysis processing approaches. The wet pyrolysis processing is also known as hydrothermal carbonization (HTC), and it has been established as a fast, simple and carbon dioxide negative conversion technique to produce hydrochars from a variety of biomasses. In fact, the technique of HTC has opened up the field of potential feedstocks for char production to a range of nontraditional renewable and plentiful wet agricultural residues and municipal wastes in the recent years. $^{8,9}$ 
However, in order to produce hydrochars through HTC in a more cost-effective way, it is still a challenge to acquire the most suitable materials from the nature directly. For this purpose, therefore, in this work we paid special attention to algal bloom residues (ABR), or, cyanobacterial blooms residues. It has been reported that cyanobacterial blooms caused by anthropogenic nutrient inputs to aquatic ecosystems have been expanding worldwide. Over the recent decades, the occurrence of harmful algal blooms has increased globally, ${ }^{7}$ while refloatation and collection of algae from lakes are considered as the most efficient approaches to reduce the threat of blue algae. ${ }^{\mathbf{1 0}}$ For example, Chao-Lake in our Anhui province, which is the fifth largest freshwater lake in China, generated a total of 0.29 million tons of algae during bloom season in 2015. The huge volumes of harmful ABR could result in a serious secondary pollution, ${ }^{10}$ so it has become an urgent task to dispose the toxic algae bloom residues. The methods such as anaerobic digestion to produce biogas, ${ }^{11}$ anaerobic co-digestion with corn straw, ${ }^{12}$ pyrolysis of blue-green algae blooms to produce biogas and biooil and biochar ${ }^{\mathbf{1 3 , 1 4}}$ have been tried to convert harmful algal blooms into useful materials such as high performance electrodes for sodium ion batteries ${ }^{15}$ and pure phycobiliproteins. ${ }^{16}$ And especially, Zhang et al. have succeeded in extraction of phycocyanin from ABR collected from Chao-Lake. ${ }^{17}$ However, after extraction of phycocyanin, there are still a large amount of $\mathrm{ABR}$, called "phycocyanin extracted algal blooms residues (PEABR)", and these PE-ABR are still rich in carbohydrate, protein or lipid which may be further utilized to produce high values of usage. ${ }^{18}$ In this work, we intended to employ the technique of HTC to produce hydrochars. Because HTC is an exothermic process used to convert wet feedstocks into carbonaceous solid, it can operate at relatively low temperature compared to other thermal methods. ${ }^{\mathbf{8} 19}$ Actually, the HTC technique has been proved to be effective in many feedstock materials ${ }^{\mathbf{2 0}}$ including cellulose, lignin, and lignocellulosic materials, as well as a variety of waste-biomasses such as municipal solid waste, distiller's grains, and corncob residues. ${ }^{19,21,22}$ Therefore, in this work, we initiated the application of HTC in transformation of ABR and especially PE-ABR to hydrochars, and anticipated that they could be used as the good adsorbents for removal of dyes. In the study, we investigated the adsorption properties of the hydrochars as functions of varied operational conditions, and examined the materials using scanning electron microscopy (SEM), Raman spectroscopy and Fourier transform infrared spectroscopy (FTIR). The involved adsorption mechanisms were discussed by evaluating the adsorption kinetics via experimental study and modeling simulation. Our results have showed that the hydrochar derived from PE-ABR has extraordinary high efficiency for removal of MG so that it may become a very promising adsorbent material for treatment of dyecontaminated wastewater.

\section{Materials and methods}

\section{Materials}

MG hydrochloride (C.I. = 42000 , chemical formula = $\mathrm{C}_{23} \mathrm{H}_{26} \mathrm{~N}_{2} \mathrm{Cl}$, molecular weight 364.92 ; absorbance maximum $\left.\left(\lambda_{\max }\right): 617 \mathrm{~nm}\right)$ was supplied by Sinopharm Chemical Reagent Company, Shanghai, China. The stock solutions $\left(200 \mathrm{mg} \mathrm{L}^{-1}\right)$ of MG were prepared by dissolving accurately weighed amount of the dyes in distilled water. All the chemicals used throughout this study were of analytical-grade. All working solutions of required concentrations were obtained by diluting the stock solution with distilled water.

\section{Adsorbent preparation and characterization}

Adsorbent preparation. The harmful algal blooms residue (ABR) was collected from the north shore $\left(31^{\circ} 40^{\prime} 53.61^{\prime \prime} \mathrm{N}\right.$, $117^{\circ} 17^{\prime} 57.06^{\prime \prime} \mathrm{E}$ ) of the fifth largest freshwater lake in China, namely, Chao-Lake, which is located near Hefei City in Anhui province, during the outbreak of cyanobacteria blooms in summer. The collected ABR were stored at $4{ }^{\circ} \mathrm{C}$ before usage. After extraction of phycocyanin by freeze-thaw with salt precipitation method (the extraction and purification of phycocyanin were performed by the combined use of two-step salt precipitation and two-step column chromatography, achieving the final purity of phycocyanin greater than 4 after the four-step purification process), ${ }^{17}$ the algal residue called phycocyanin-extracted algal bloom residues (PE-ABR) were left and stored at $4{ }^{\circ} \mathrm{C}$ before use. To produce hydrochars, both ABR (before phycocyanin extraction) and PE-ABR (after phycocyanin extraction) were centrifuged for 30 minutes with $8000 \mathrm{rpm}$ to collect precipitation. The HTC process was conducted as follows: ${ }^{23}$ a mixture of ABR or PE-ABR (30 g) and deionized water $(15 \mathrm{~mL})$ were placed into an autoclave; next, the reactors was programmed to heat until reaching a predefined peak temperature $\left(200{ }^{\circ} \mathrm{C}\right)$ and then hold for the specified retention time (10 hours); after the reaction, the hydrochar products were washed several times with deionized water; and finally, these samples were separated from water using filtration/centrifugation and dried at $60{ }^{\circ} \mathrm{C}$ for further analysis.

Surface characterization. The surface morphology of hydrochar from ABR or PE-ABR was visualized by a scanning electronic microscope (JEOL-2100F, Japan). FTIR spectroscopy was used to identify the chemicals present in the adsorbent. The FTIR spectra of the control samples (hydrochar before adsorption of MG) and the MG-loaded samples (adsorbent $4 \mathrm{~g} \mathrm{~L}^{-1}$, $100 \mathrm{mg} \mathrm{L^{-1 }}$ MG for $24 \mathrm{~h}$ ) were obtained using a FTIR spectrometer (Alpha-T, Bruker) accumulating 64 scans at a spectral resolution of $1 \mathrm{~cm}^{-1}$. The Raman spectra of MG and hydrochars from ABR and PE-ABR before and after loading MG (adsorbent $4 \mathrm{~g} \mathrm{~L}^{-1}, 100 \mathrm{mg} \mathrm{L}^{-1} \mathrm{MG}$ for $24 \mathrm{~h}$ ) were recorded using an Xplora Raman microspectrometer (Horiba Jobin Yvon) with a $532 \mathrm{~nm}$ laser and an Olympus $50 \times$ long working distance lens. The beam size was about $0.7 \mu \mathrm{m}$ in diameter and worked with a power of approximately $0.2 \mathrm{~mW}$. The acquisition time of $5 \mathrm{~s}$ was used for the Raman measurements at each point.

Batch adsorption experiments. Batch adsorption experiments were conducted by shaking varies masses of hydrochar produced from ABR and hydrochar from PE-ABR with $50 \mathrm{~mL}$ aqueous solution of $\mathrm{MG}$ of known concentration (50, 75 and $100 \mathrm{mg} \mathrm{L}^{-1}$ ) in $100 \mathrm{~mL}$ flasks placed in a temperature controlled shaker at $25{ }^{\circ} \mathrm{C}$ and with adsorbent doses between 1 and $8 \mathrm{~g} \mathrm{~L}^{-1}$ 
at a constant shaking rate of $200 \mathrm{rpm}$. After the desired contact time, the samples were withdrawn from the mixture and centrifuged for $15 \mathrm{~min}$ at $8000 \mathrm{rpm}$. After centrifugation, the concentration of MG in solution was measured at $617 \mathrm{~nm}$ using a UV-vis spectrophotometer (Shimadzu, UV-2550, Japan). Controls were measured using adsorbent in distilled water blank and adsorbent-free MG. The percentage removal of MG was calculated by using the following equation:

$$
R \%=\left(\frac{C_{0}-C_{t}}{C_{0}}\right) \times 100
$$

where $C_{0}$ and $C_{t}$ are the MG concentrations $\left(\mathrm{mg} \mathrm{L}^{-1}\right)$ initially and at given time $t$, respectively. The amount of MG taken by adsorbent $\left(q_{\mathrm{e}}\right)$ was calculated by:

$$
q_{\mathrm{e}}=\frac{V\left(C_{0}-C_{\mathrm{e}}\right)}{m}
$$

where $V$ is the solution volume (L), $m$ is the amount of adsorbent (g), and $C_{0}$ and $C_{\mathrm{e}}$ are the initial and equilibrium concentrations of MG $\left(\mathrm{mg} \mathrm{L}^{-1}\right)$, respectively. Three replicates per sample were available for obtaining the average in the evaluation.

Adsorption isotherm. Four isotherm models including Langmuir, Freundlich, Dubinin-Radushkevich and Temkin models were tested for equilibrium description at ambient temperature. Langmuir model can be described by the following equation:

$$
\frac{C_{\mathrm{e}}}{q_{\mathrm{e}}}=\frac{1}{Q_{0} K_{\mathrm{L}}}+\left(\frac{1}{Q_{0}}\right) C_{\mathrm{e}}
$$

where $q_{\mathrm{e}}$ and $C_{\mathrm{e}}$ correspond to the amount adsorbed per gram of adsorbent $\left(\mathrm{mg} \mathrm{g}^{-1}\right)$ and the solute concentration $\left(\mathrm{mg} \mathrm{L}^{-1}\right)$ in the aqueous solution in equilibrium, respectively. $Q_{0}$ and $K_{\mathrm{L}}$ are constants related to the maximum adsorption capacity $\left(\mathrm{mg} \mathrm{g}^{-1}\right)$ and the adsorption energy $\left(\mathrm{L} \mathrm{mg}^{-1}\right)$, respectively. ${ }^{24}$ The essential characteristics of Langmuir isotherm can be explained in terms of dimensionless constant separation factor $\left(R_{\mathrm{L}}\right)$ which is expressed as: ${ }^{7,25}$

$$
R_{\mathrm{L}}=\frac{1}{1+K_{\mathrm{L}} C_{\mathrm{i}}}
$$

where $C_{\mathrm{i}}$ is initial concentration of MG.

Freundlich's model can be described by the following equation:

$$
\ln q_{\mathrm{e}}=\ln K_{\mathrm{F}}+\left(\frac{1}{n}\right) \ln C_{\mathrm{e}}
$$

where $K_{\mathrm{F}}\left(\mathrm{mg} \mathrm{g}^{-1}\right)$ is the adsorption capacity of the adsorbent and $n$ gives an index for the effectiveness of the adsorption process. $^{25}$

Dubinin and Radushkevich (D-R) equation ${ }^{26}$ is represented by the following equation:

$$
\ln q_{\mathrm{e}}=\ln Q_{0}-K_{\mathrm{DR}} \varepsilon^{2}
$$

where $K_{\mathrm{DR}}\left(\mathrm{mol}^{2} \mathrm{~kJ}^{-2}\right)$ is a constant related to mean adsorption energy; and $\varepsilon$ is the Polanyi potential, which can be calculated from equation:

$$
\varepsilon=R T \ln \left(1+\frac{1}{C_{\mathrm{e}}}\right)
$$

The slope of the plot of $\ln q_{\mathrm{e}}$ versus $\varepsilon^{2}$ gives $K_{\mathrm{DR}}\left(\mathrm{mol}^{2} \mathrm{~kJ}^{-2}\right)$ and the intercept yields the maximum adsorption capacity, $Q_{0}$ $\left(\mathrm{mg} \mathrm{g}^{-1}\right) . T$ is the absolute temperature in $K$ and $R$ is the universal gas constant $\left(8.314 \mathrm{~J} \mathrm{~mol}^{-1} \mathrm{~K}^{-1}\right)$. The mean adsorption energy $(E)$ can also be worked out using the following relationship:

$$
E=\frac{1}{\sqrt{-2 K_{\mathrm{DR}}}}
$$

The Temkin equation is given by the following equation:

$$
q_{\mathrm{e}}=B_{\mathrm{T}} \ln K_{\mathrm{T}}+B_{\mathrm{T}} \ln C_{\mathrm{e}}
$$

where $B_{\mathrm{T}}=R T / b_{\mathrm{T}}, b_{\mathrm{T}}$ is related to the heat of adsorption, $K_{\mathrm{T}}$ is the equilibrium binding constant corresponding to the maximum binding energy. ${ }^{27}$

Adsorption kinetics. The controlling mechanism of the adsorption process was investigated by fitting the experimental data with pseudo-first-order, pseudo-second-order kinetic models or the intra-particle diffusion model, respectively. For the pseudo-first-order and pseudo-second-order kinetic models, the kinetics equations are defined as follows:

$$
\begin{gathered}
\log \left(q_{\mathrm{e}}-q_{t}\right)=\log q_{\mathrm{e}}-\frac{k_{1}}{2.303} t \\
\frac{t}{q_{t}}=\frac{1}{k_{2} q_{\mathrm{e}}^{2}}+\frac{1}{q_{\mathrm{e}}} t
\end{gathered}
$$

where $q_{t}\left(\mathrm{mg} \mathrm{g}^{-1}\right)$ is the amount of adsorbed MG on hydrochar at time $t(\mathrm{~min}) . k_{1}(1 / \mathrm{min})$ and $k_{2}\left(\mathrm{~g} \mathrm{mg}^{-1} \mathrm{~min}^{-1}\right)$ are adsorption rate constants of pseudo-first-order and pseudo-second-order models, respectively. The adsorption rate constant $\left(k_{1}\right)$ for MG adsorption was calculated from the slope of the linear plot of $\ln \left(q_{\mathrm{e}}-q_{t}\right)$ versus $t$. In the latter case, kinetic data were plotted as $t / q_{t}$ against $t .^{25,28}$

According to the intra-particle diffusion model proposed by Weber and Morris, ${ }^{7,29}$ the initial rate of intra-particle diffusion is calculated by

$$
q_{t}=K_{\mathrm{w}} t^{1 / 2}+C
$$

where $K_{\mathrm{w}}\left(\mathrm{mg} \mathrm{g}^{-1} \mathrm{~min}^{-1 / 2}\right)$ represents intra-particle diffusion rate constant, $C$ is the intercept and $t$ denotes contact time (min). The values of $q_{t}$ versus $t^{1 / 2}$ and the rate constants $K_{\mathrm{w}}$ are directly evaluated from the slope of the regression line.

\section{Results and discussion}

\section{Characterization of adsorbent}

SEM characterization. The surface characterization was conducted through SEM (Fig. 1). Fig. 1a illustrates the morphological feature of the ABR-hydrochar, showing that part of algal cells could still maintain the morphology after HTC. 

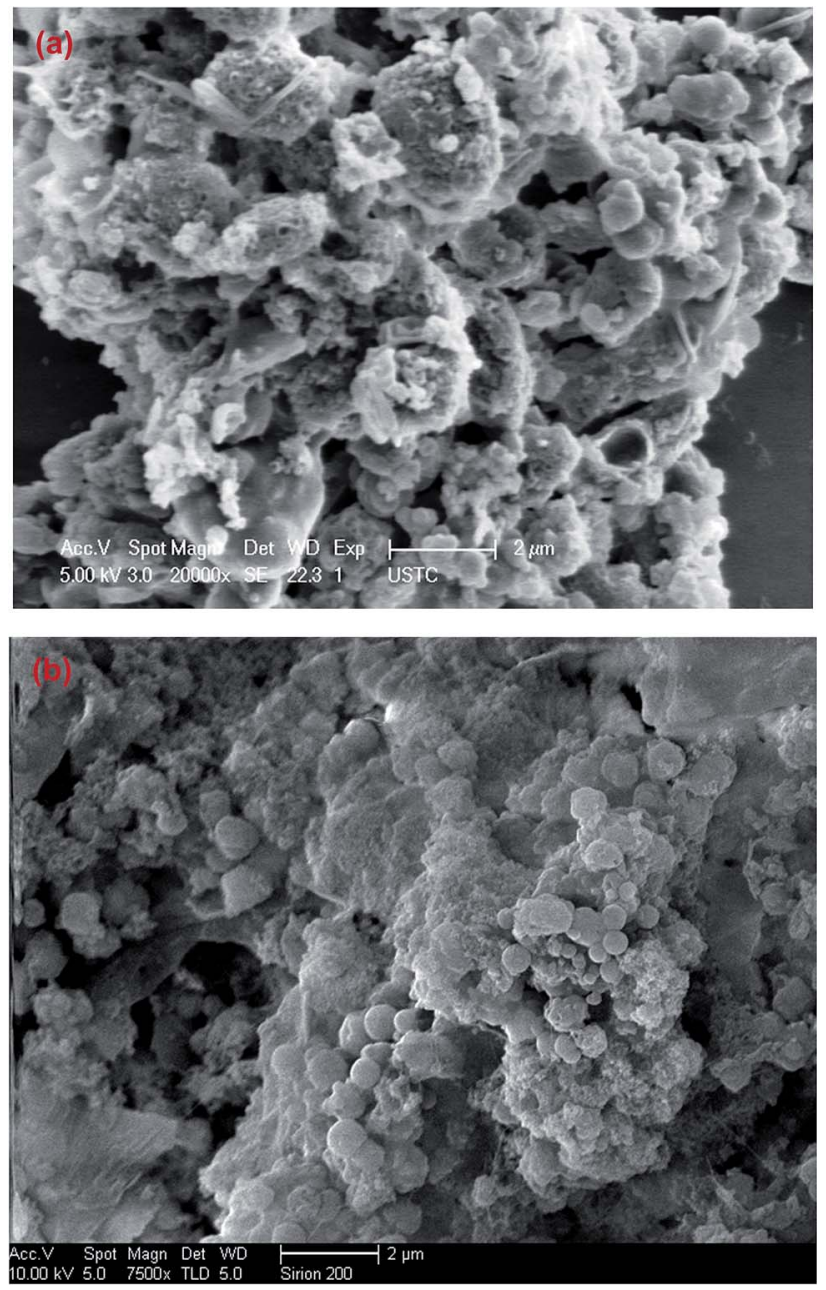

Fig. 1 Scanning electron micrographs of the surfaces of hydrochars deviated from ABR and PE-ABR by HTC ((a) hydrochar-ABR; (b) hydrochar-PE-ABR).

Fig. 1b displays the hydrochar made from PE-ABR, indicating that the algae cells lost their inherent surface morphology, and most of them were converted into nonuniform micro or nanoscale particles, they contained the higher porosity than ABRhydrochar. This ultra-structural property may provide favorable for the dye molecules to be trapped and adsorbed by hydrochar derided from PE-ABR compared with that from ABR as we will discuss more in the following sections.

Spectroscopic analysis of ABR and hydrochars by FTIR and Raman spectroscopy. Vibrational spectroscopy such as Raman and FTIR spectroscopy can be very useful in the study of interactions involved in adsorption process. Here, FTIR spectroscopy was employed to analyze the composition of the hydrochars converted from $\mathrm{ABR}$ or PE-ABR and the possible interaction between the hydrochars and MG. The FTIR spectra of samples are presented in Fig. 2. It can be seen that the broad region centered at about $3400 \mathrm{~cm}^{-1}$, which can be attributed to stretching vibration of bonded hydroxyl groups and $\mathrm{N}-\mathrm{H}$ stretching vibration in amino compounds, are highly affected by the HTC processing. The $-\mathrm{OH}$ absorption peaks at 3400 and $3393 \mathrm{~cm}^{-1}$ of ABR and PE-ABR are diminished and the sharp

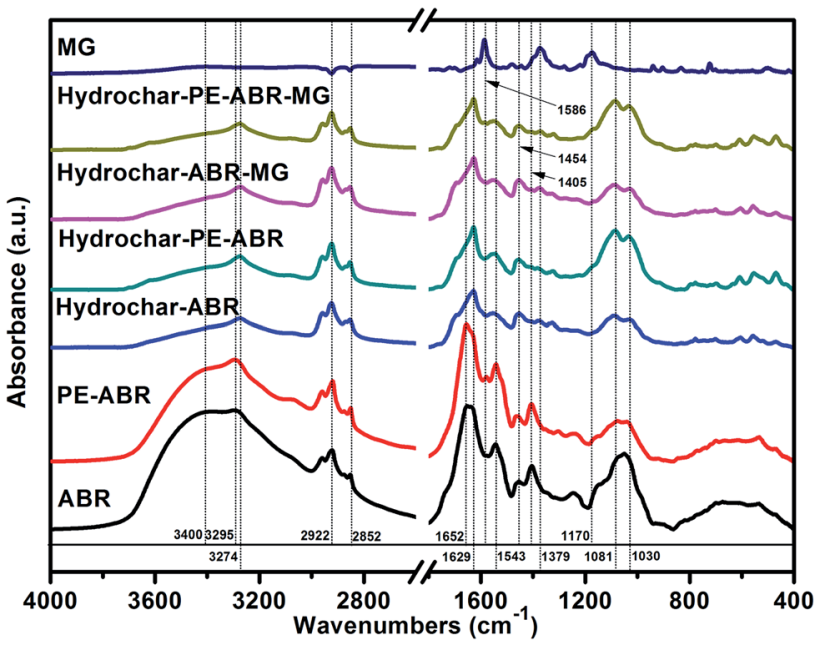

Fig. 2 FTIR spectra of MG, ABR, PE-ABR, hydrochar-ABR, hydrochar$P E-A B R$ and $M G$ loaded hydrochar (MG concentration $=100 \mathrm{mg} \mathrm{L}^{-1}$, adsorbent dosage $=4 \mathrm{~g} \mathrm{~L}^{-1}$; temperature $=25^{\circ} \mathrm{C}$; contact time $=$ $24 \mathrm{~h}$; stirring speed $=200 \mathrm{rpm}$ ).

peaks are shifted from 3295 and $3294 \mathrm{~cm}^{-1}$ to 3274 and 3276 $\mathrm{cm}^{-1}$ after the HTC treatment (Fig. 2, Table 1). This is most likely due to dehydration of ABR and PE-ABR during the HTC process. ${ }^{30}$ After MG adsorption, the spectra show the changes in intensity and shift in position. The - $\mathrm{OH}$ absorption peaks are shifted from 3274 and $3276 \mathrm{~cm}^{-1}$ to 3273 and $3275 \mathrm{~cm}^{-1}$ for ABR-hydrochar and PE-ABR-hydrochar, respectively. The peaks at 2922 and $2852 \mathrm{~cm}^{-1}$ correspond to asymmetric and symmetric $\mathrm{C}-\mathrm{H}$ stretching vibrations in aliphatic compounds. The intensities of peaks around 2924 and $2853 \mathrm{~cm}^{-1}$ are increased in the hydrochars. Previous study has shown that these peaks are clearly visible in biomass as well as in the biochars produced at low temperature, but gradually diminished and indiscernible when HTC temperature is above $450{ }^{\circ} \mathrm{C} \cdot{ }^{31} \mathrm{In}$ the present study, the temperature of HTC was $200{ }^{\circ} \mathrm{C}$, so the $\mathrm{C}-\mathrm{H}$ stretching vibrations were still present in the samples before and after HTC treatment. There are no obvious shifts of these two peaks with adsorption of MG onto the both hydrochars. The amide I bands at 1652 and $1656 \mathrm{~cm}^{-1}$ of ABR and PE$\mathrm{ABR}$ are assigned to $\mathrm{C}=\mathrm{O}$ stretching vibrations, and they are shifted to 1629 and $1628 \mathrm{~cm}^{-1}$ in the hydrochars. The peak around $1600 \mathrm{~cm}^{-1}$ corresponds to the $\mathrm{C}=\mathrm{C}$ stretching vibration in aromatic compounds. ${ }^{10}$ The peak shifts indicate that the destruction of the protein in feedstocks leads to more exposure of aromatic compounds in the hydrochar samples. After MGadsorption onto the hydrochars, these peaks are shifted to $1627 \mathrm{~cm}^{-1}$, indicating the involvement of $\mathrm{C}=\mathrm{C}$ of in hydrochar samples during the adsorption process. The peaks at 1543 and $1542 \mathrm{~cm}^{-1}$ corresponding to $\mathrm{C}-\mathrm{N}$ stretching (amide II) in ABR and PE-ABR are shifted to 1555 and $1545 \mathrm{~cm}^{-1}$ in hydrochars, and they are shifted to 1553 and $1544 \mathrm{~cm}^{-1}$ with adsorption of MG. The aromatic $\mathrm{C}-\mathrm{H}$ groups with in-plane bending vibration can be observed at 1454 and $1463 \mathrm{~cm}^{-1}$, and the positions of these peaks are shifted to 1453 and $1457 \mathrm{~cm}^{-1}$ with intensity increase as well in the hydrochars, suggesting that the new 
Table 1 The FTIR spectral characteristics of hydrochars and their feedstocks, and hydrochars before and after adsorption of MG

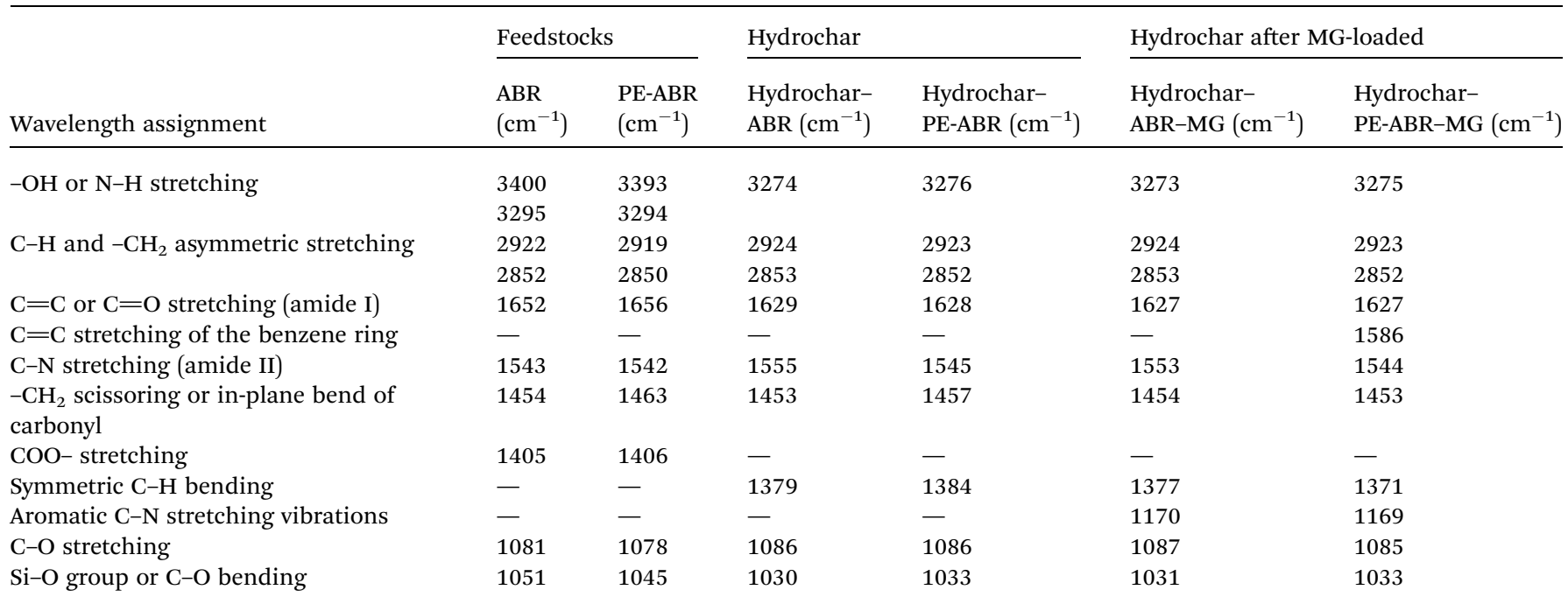

functional group are formed by the HTC treatment. These peaks are also visible in the spectra of biochars produced by pyrolysis. ${ }^{31}$ Obvious shifts to 1454 and $1453 \mathrm{~cm}^{-1}$ are also present in the hydrochars with the adsorption of MG, confirming the interaction between the aromatic $\mathrm{C}-\mathrm{H}$ groups and MG. A broad peak at about $1080 \mathrm{~cm}^{-1}$ corresponding to $\mathrm{C}-\mathrm{O}$ stretching are separated into two peaks at about 1081 and $1030 \mathrm{~cm}^{-1}$ after the HTC treatment. The peak at $1030 \mathrm{~cm}^{-1}$ is assigned to $\mathrm{Si}-\mathrm{O}$ stretching, ${ }^{32}$ so it indicates that $\mathrm{SiO}_{2}$ is formed in the HTC treatment. The bands shifts of $\mathrm{C}-\mathrm{O}$ stretching after adsorption of MG by hydrochars also suggests the involvement of $\mathrm{C}-\mathrm{O}$ group and Si-O stretching in binding MG. The new peaks at $1586 \mathrm{~cm}^{-1}$ indicate $\mathrm{C}=\mathrm{C}$ stretching of the benzene ring of MG; and the peak at $1169 \mathrm{~cm}^{-1}$ indicates $\mathrm{C}-\mathrm{N}$ stretching vibrations of MG. The intensity of peak at $1586 \mathrm{~cm}^{-1}$ of PE-ABR-hydrochar after adsorption of MG is higher than that of ABR-hydrochar, indicating that higher adsorption capability of MG by PE-ABRhydrochar. All these observations indicate the interaction between MG and the hydrochars and the results are summarised in Fig. 2 and Table 1.

The Raman spectrum of carbonaceous material is typically characterized by two bands: the $\mathrm{G}$ band (about $1580 \mathrm{~cm}^{-1}$ ) is associated with $\mathrm{sp}^{2} \mathrm{C}$ atoms and the $\mathrm{D}$ band (about $1350 \mathrm{~cm}^{-1}$ ) corresponds to $\mathrm{sp}^{3} \mathrm{C}$ atoms, deriving from the defects and/or disorders of graphite crystal. ${ }^{33}$ Generally, the relative intensity ratio of $\mathrm{D}$ to $\mathrm{G}$ bands $\left(I_{\mathrm{D}} / I_{\mathrm{G}}\right)$ is a measure of disorder degree and average size of the $\mathrm{sp}^{2}$ domains in graphitized structure. ${ }^{34}$ The Raman spectra of two types of hydrochars exhibit two characteristic peaks related to the $\mathrm{D}$ band and $\mathrm{G}$ band, respectively, implying the formation of carbonaceous materials after $\mathrm{ABR}$ and PE-ABR treated by HTC (Fig. 3). The $I_{\mathrm{D}} / I_{\mathrm{G}}$ intensity ratio of PE-ABR hydrochar is 0.87 , which is higher than that of ABRhydrochar, suggesting that the higher disorder degree of the $\mathrm{sp}^{3}$ domains of PE-ABR hydrochar. After the adsorption of MG, the $I_{\mathrm{D}} / I_{\mathrm{G}}$ intensity ratios decrease respectively from 0.78 and 0.87 to 0.71 and 0.74 for ABR-hydrochar and PE-ABR-hydrochar, the decrease of the $I_{\mathrm{D}} / I_{\mathrm{G}}$ intensity ratios means interactions between amorphous structures in the carbon structures and MG. The new peak at $1200 \mathrm{~cm}^{-1}$ appears in the MG adsorbed hydrochar samples, and the intensity of this peak in PE-ABR-

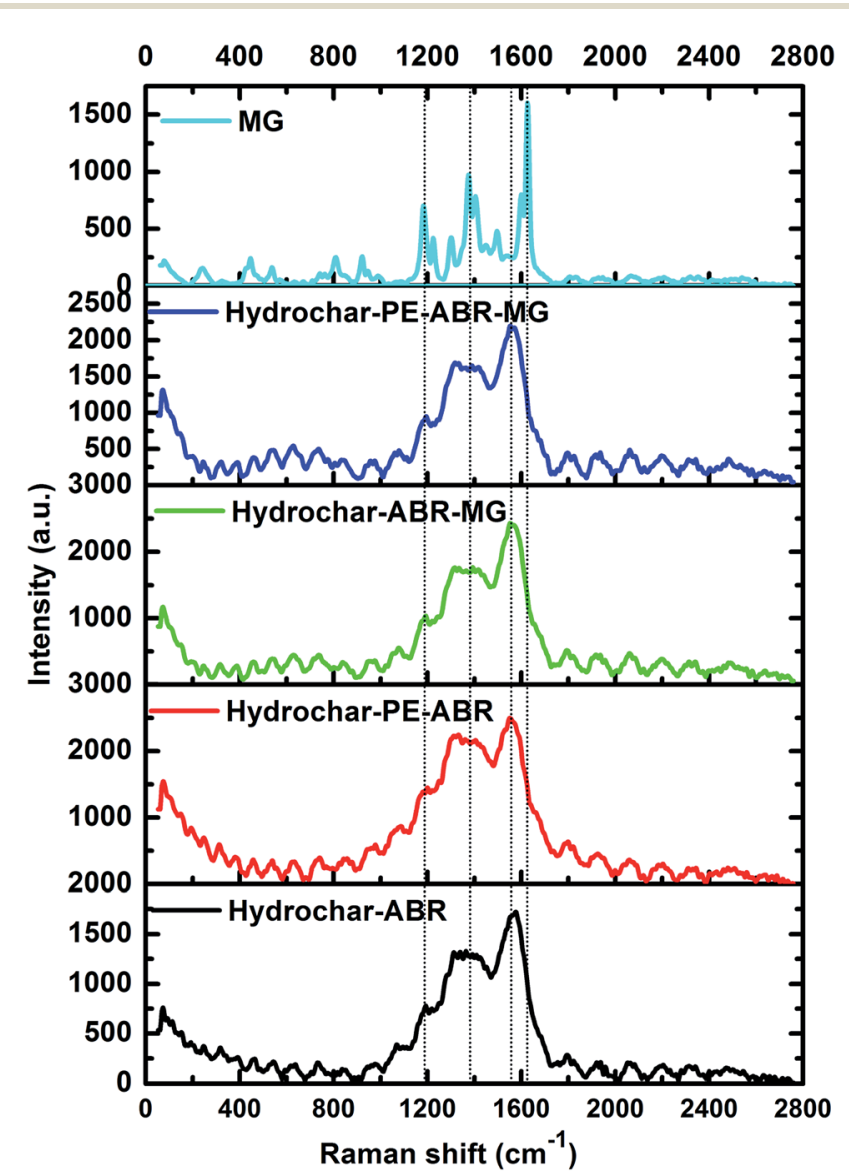

Fig. 3 Raman spectra of hydrochar-ABR and hydrochar-PE-ABR before and after MG adsorption (MG concentration = $100 \mathrm{mg} \mathrm{L}^{-1}$; adsorbent dosage $=4 \mathrm{~g} \mathrm{~L}^{-1}$; temperature $=25^{\circ} \mathrm{C}$; contact time $=$ $24 \mathrm{~h}$; stirring speed $=200 \mathrm{rpm}$ ). 
hydrochar-MG samples is significantly higher than that of the ABR-hydrochar-MG samples, implying more favorable adsorption of MG on PE-ABR-hydrochar than ABR-hydrochar (Fig. 3). These results also imply the interaction between MG and the hydrochars, which are consistent with the above FTIR analysis and the foregoing morphology analysis results given by the SEM observation.

Influence of adsorbent dosage and initial MG concentration on adsorption efficiency. The influence of adsorbent dosage and initial concentration of MG on the efficiency of MG removal was also investigated. As shown in Fig. 4a, the percent removal of MG increased from $43.1 \%$ to $78.6 \%$ in ABR-hydrochar concentration from 1 to $8 \mathrm{~g} \mathrm{~L}^{-1}$ after $48 \mathrm{~h}$ contact. The removal rates of MG by PE-ABR-hydrochar were increased from $62.7 \%$ to 92.4\% with increase dosage from 1 to $8 \mathrm{~g} \mathrm{~L}^{-1}$ (Fig. $4 \mathrm{~b}$ ). The results suggest that the PE-ABR-hydrochar has higher adsorption capability of MG than ABR-hydrochar, and this can be explained by that the PE-ABR hydrochar has more rough and irregular surface morphology than the ABR hydrochar as mentioned in the former section. Effects of initial concentration on MG removal by the ABR-hydrochar and the PE-ABR-hydrochar were studied by carrying out the experiments at different initial concentrations $\left(50,75\right.$ and $\left.100 \mathrm{mg} \mathrm{L}^{-1}\right)$. The percent MG removal decreased from $50.9 \%$ to $33.9 \%$ after the treatment by the ABR-hydrochar and from $92.1 \%$ to $82.6 \%$ after the treatment by the PE-ABR-hydrochar as the initial concentration of MG increases from 50 to $100 \mathrm{mg} \mathrm{L}^{-1}$ for $4 \mathrm{~g} \mathrm{~L}^{-1}$ of adsorbent at equilibrium contact time of $24 \mathrm{~h}$ (Fig. 4c and d). At low concentration, the ratio of available surface to the initial MG concentration is larger, so the removal may become higher. As the limited active sites on hydrochars become saturated at a relatively higher concentration, the increment in adsorption capacity become restricted, so the percentage removal become lesser..$^{35}$

Adsorption isotherm. To examine the relationship between adsorbent and adsorbate at equilibrium, and to search for the maximum adsorption capacity, four adsorption isotherm models including Langmuir, Freundlich, D-R and Temkin isotherms were applied and evaluated. The plots of $C_{\mathrm{e}} / q_{\mathrm{e}}$ versus $C_{\mathrm{e}}, \ln q_{\mathrm{e}}$ versus $\ln C_{\mathrm{e}}, \ln q_{\mathrm{e}}$ versus $\varepsilon^{2}$ and $q_{\mathrm{e}}$ versus $\ln C_{\mathrm{e}}$ turn out to be linear (Fig. 5). The values of $Q_{0}, K_{\mathrm{L}}, K_{\mathrm{F}}, K_{\mathrm{DR}}, K_{\mathrm{T}}, n$ and the regression correlation coefficients were calculated from the slope and intercept of these plots and reported in Table 2. These values of regression coefficients were used as the fitting criteria to find out the applicability of the foregoing four isotherms. It is found that the plot depicts the linear form of the Langmuir isotherm with extremely high correlation coefficients for MG adsorption by the hydrochar-ABR and the hydrochar-PE-ABR $\left(R^{2}=0.979\right.$ and 0.999$)$, indicating that the adsorption of MG on hydrochars was likely to be monolayer and the distribution of active sites on the adsorbent was homogeneous. ${ }^{27} R_{\mathrm{L}}$ is a positive number whose magnitude determines the feasibility of the adsorption process. ${ }^{7,26}$ The $R_{\mathrm{L}}$ values for each of the different initial concentrations are between 0 and 1 , indicating favorable adsorption of MG onto the hydrochars. Freundlich model can also fit well with the experimental data (Table 2). The values of heterogeneity factor $n$ of Freundlich model were more than 1 for the two hydrochars at different temperatures, (a)

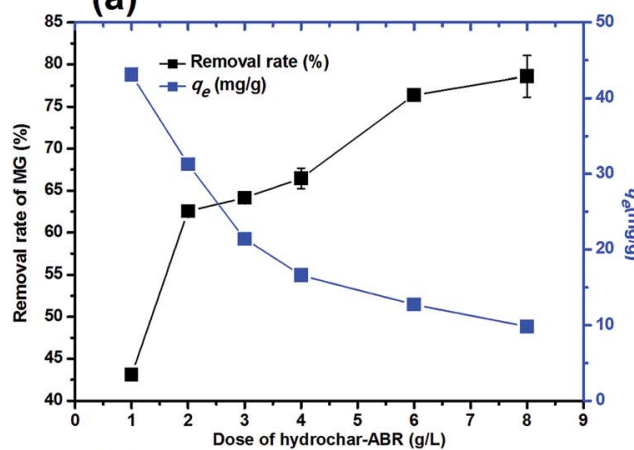

(c)

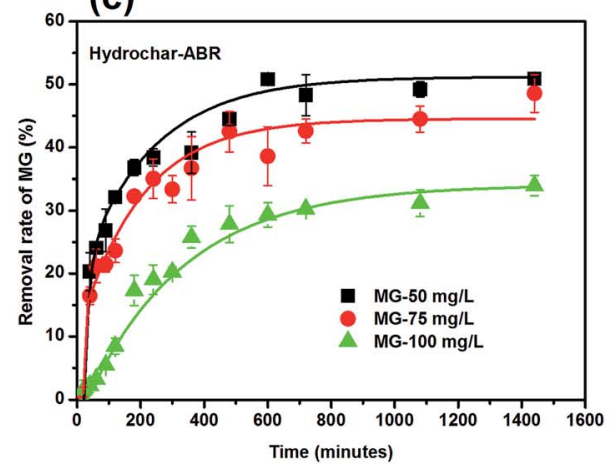

(b)

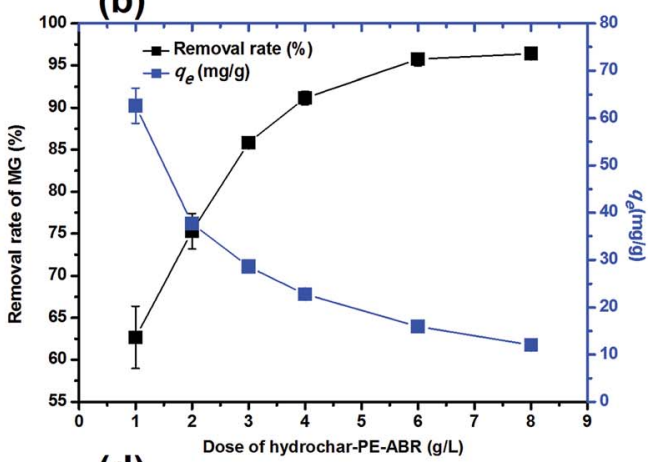

(d)

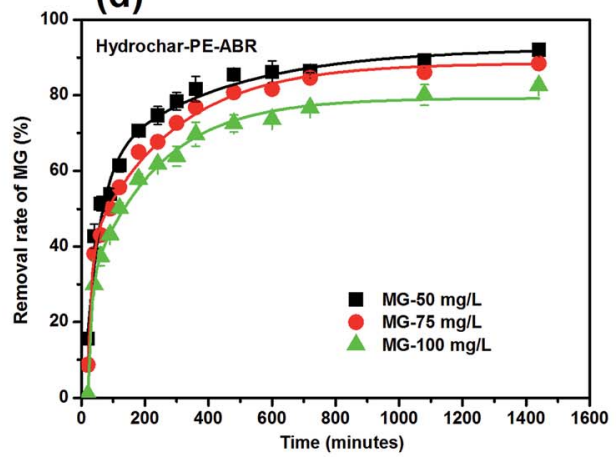

Fig. 4 Effects of hydrochar dosages and the initiation concentrations of MG on the adsorption of MG. (a) Dose of hydrochar-ABR; (b) dose of hydrochar-PE-ABR; (c) effects of initiation concentrations of MG on adsorption by hydrochar-ABR; and (d) adsorption by hydrochar-PE-ABR. 

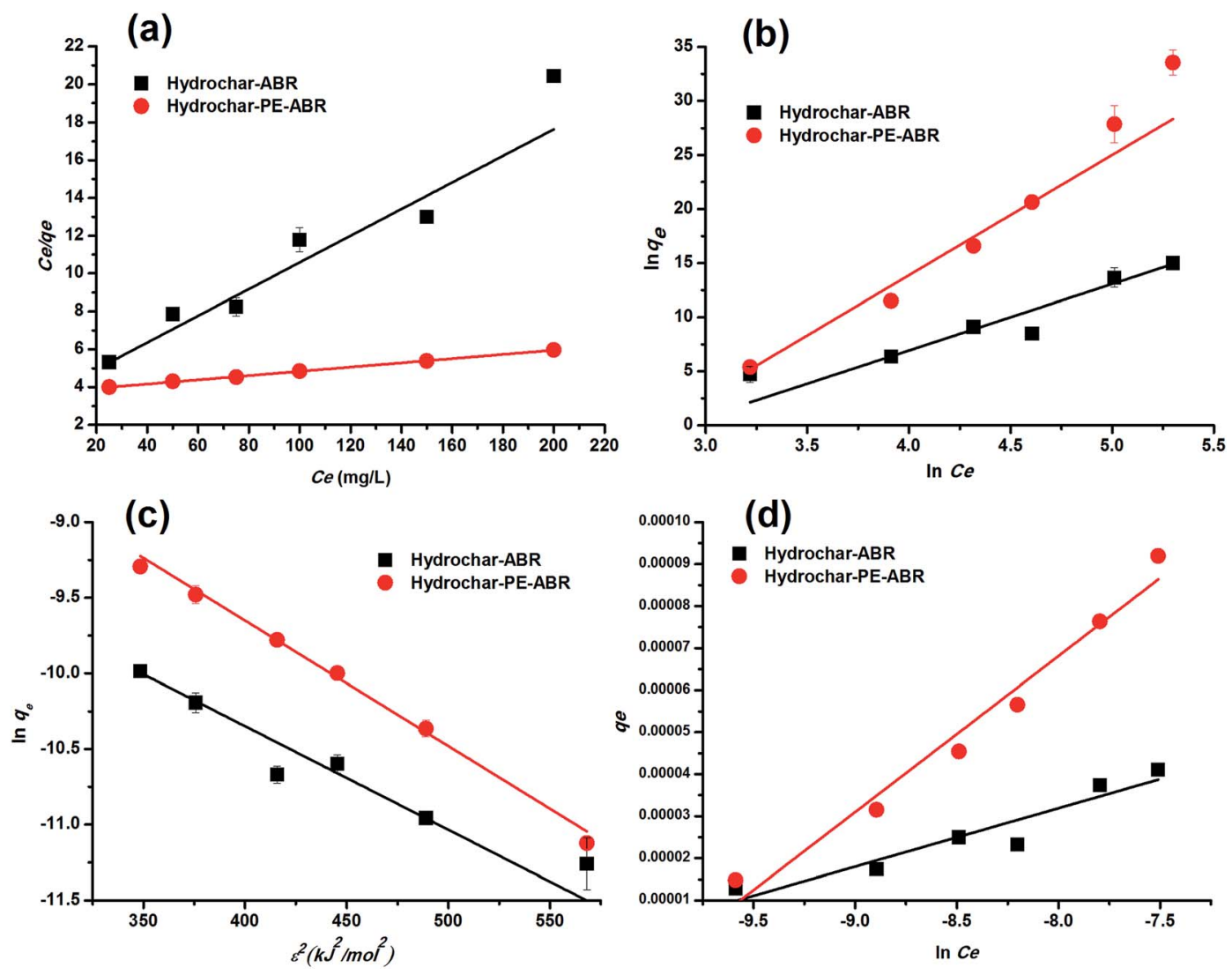

Fig. 5 Langmuir (a), Freundlich (b), D-R (c) and Temkin (d) fitting isotherms of MG on hydrochar-ABR and hydrochar-PE-ABR (adsorbent dosage $=4 \mathrm{~g} \mathrm{~L}^{-1}$; contact time $=24 \mathrm{~h}$; stirring speed $=200 \mathrm{rpm}$ ).

Table 2 Isotherm parameters for removal of MG by hydrochar-ABR and hydrochar-PE-ABR (time $=24 \mathrm{~h}$; adsorbent dosage $=4 \mathrm{~g} \mathrm{~L}^{-1}$; stirring speed $=200 \mathrm{rpm}$ )

\begin{tabular}{llll}
\hline Models & Parameters & $\begin{array}{l}\text { Hyrochar- } \\
\text { ABR }\end{array}$ & $\begin{array}{l}\text { Hydrochar- } \\
\text { PE-ABR }\end{array}$ \\
\hline Langmuir model & $Q_{0}\left(\mathrm{mg} \mathrm{g}^{-1}\right)$ & 43.113 & 89.047 \\
& $K_{\mathrm{L}}\left(\mathrm{L} \mathrm{mg}^{-1}\right)$ & 0.015 & 0.003 \\
& $R^{2}$ & 0.979 & 0.999 \\
Freundlich model & $R_{\mathrm{L}}$ & $0.247-0.725$ & $0.623-0.930$ \\
& $K_{\mathrm{F}}\left(\mathrm{mg} \mathrm{g}^{-1}\right)$ & 11.925 & 17.796 \\
D-R model & $n$ & 1.796 & 1.159 \\
& $R^{2}$ & 0.983 & 0.984 \\
& $Q_{\mathrm{o}}\left(\mathrm{mg} \mathrm{g}^{-1}\right)$ & 181.045 & 646.093 \\
& $K_{\mathrm{DR}}\left(\mathrm{mol}^{2} \mathrm{~kJ}^{2} \times 10^{-3}\right)$ & 6.85 & 8.29 \\
& $R^{2}$ & 0.976 & 0.991 \\
& $E\left(\mathrm{~kJ} \mathrm{~mol}^{-1}\right)$ & 8.544 & 7.766 \\
& $b_{\mathrm{T}}\left(10^{5} \mathrm{~kJ} \mathrm{~mol}^{-1}\right)$ & 1.792 & 6.698 \\
& $K_{\mathrm{T}}\left(\mathrm{L} \mathrm{mg}^{-1}\right)$ & 81.514 & 51.206 \\
& $R^{2}$ & 0.973 & 0.992
\end{tabular}

indicating that the adsorption was favorable. ${ }^{27}$ Both Langmuir and Freundlich isotherms fit well with the experimental data indicating both monolayer and heterogeneous surface conditions may exist.

Dubinin and Radushkevich have proposed another isotherm which is applied to estimate the mean free energy of adsorption.
D-R isotherm constant $\left(K_{\mathrm{DR}}\right)$ can be used to determine the mean free energy of adsorption per mole of the adsorbate $(E, \mathrm{~kJ}$ $\mathrm{mol}^{-1}$ ), which in turn gives an idea about the type of adsorption i.e. physisorption or chemisorptions. ${ }^{26}$ If the value of $E$ is between 8 and $16 \mathrm{~kJ} \mathrm{~mol}^{-1}$ then the adsorption process follows by chemical ion-exchange, and if $E<8 \mathrm{~kJ} \mathrm{~mol}^{-1}$ the adsorption process is of physical nature, whereas if the value is more than $16 \mathrm{~kJ} \mathrm{~mol}^{-1}$, then chemisorption prevails. ${ }^{7,36}$ Our results showed that $E$ value was 5.84 and $7.766 \mathrm{~kJ} \mathrm{~mol}^{-1}$ below $8 \mathrm{~kJ} \mathrm{~mol}^{-1}$ (Table 2 ), indicating that the physical adsorption was the main process for the adsorption of MG by hydrochars in this work. The positive values of $E$ indicate that the sorption process was endothermic and that higher solution temperature would favor the sorption process. ${ }^{7}$

Temkin isotherm contains a factor that explicitly takes into account adsorbing species-adsorbate interactions. This model assumes that the energy of the molecule adsorption will decrease linearly with coverage because of the adsorbate and adsorbent interactions. ${ }^{37}$ So, we applied Temkin isotherm as well to evaluate the adsorption potentials of the adsorbents for adsorbate ions. The value of Temkin adsorption potential constant $K_{\mathrm{T}}$ is 81.51, and $51.21 \mathrm{~L} \mathrm{mg}^{-1}$ for adsorption MG by hydrochar-ABR and hydrochar PE-ABR hydrochar. The values of Temkin constant $b_{\mathrm{T}}$ that is related to the heat of MG adsorption onto the two hydrochars were shown in Table 2, confirming a strong interaction between MG ions and the adsorbents surface. 

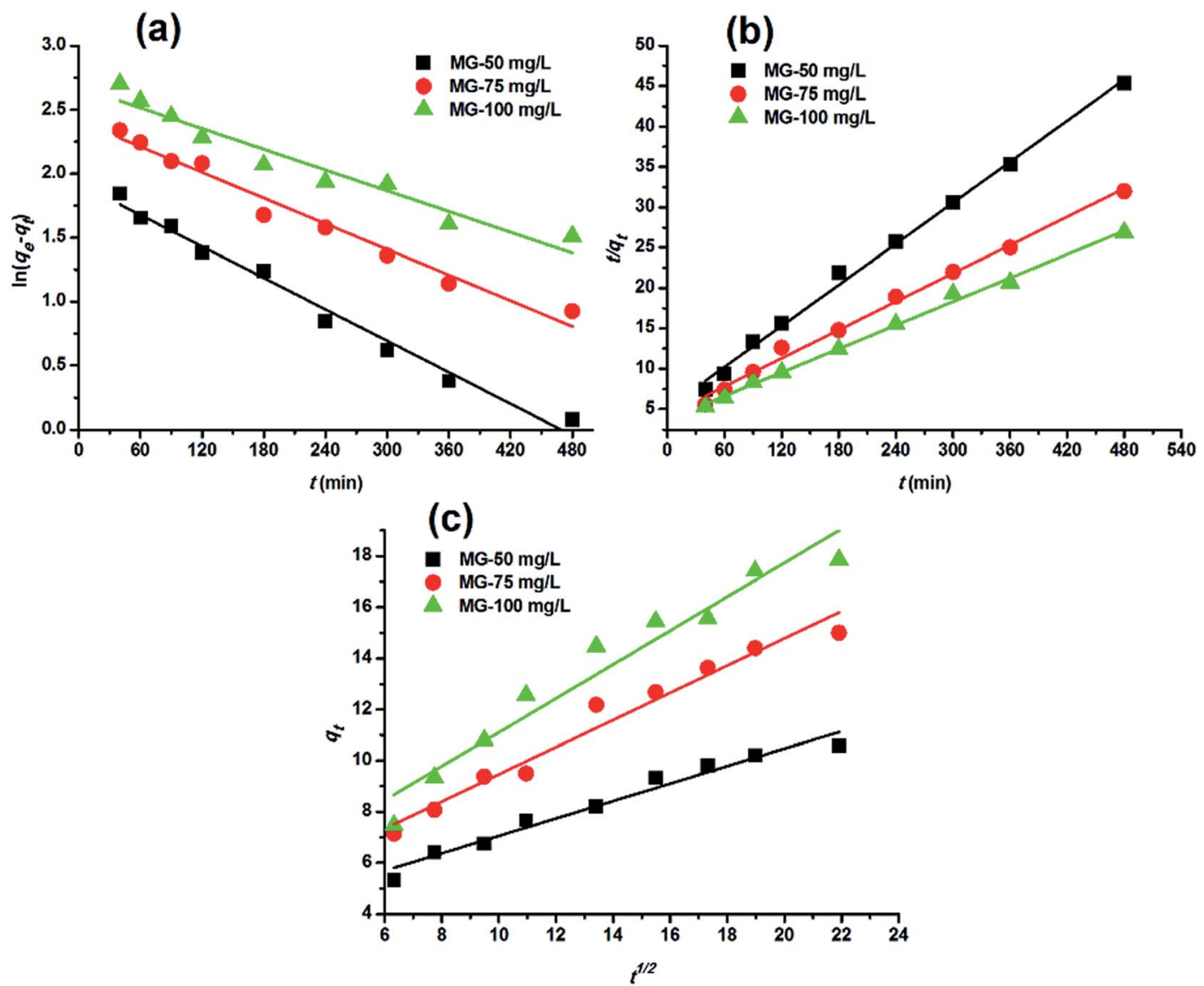

Fig. 6 Adsorption kinetic plots for adsorption of MG on hydrochar-PE-ABR. (a) Pseudo-first-order kinetics; (b) pseudo-second-order kinetics; (c) intra-particle diffusion kinetics (adsorbent dosage $=4 \mathrm{~g} \mathrm{~L}^{-1}$; stirring speed $=200 \mathrm{rpm}$ ).

Adsorption kinetics. In order to analyze the adsorption kinetics of MG onto the hydrochars, the pseudo-first-order, pseudo-second-order and intra-particle diffusion models were applied to the experimental data. The adsorption kinetics described by the relationship between contact time and MG uptake by $4 \mathrm{~g} \mathrm{~L}^{-1}$ the two hydrochars for three initial MG concentrations $\left(50,75\right.$ and $\left.100 \mathrm{mg} \mathrm{L}^{-1}\right)$ were discussed later. The linear fitting results of PE-ABR hydrochar $\left(\log \left(q_{\mathrm{e}}-q_{t}\right)\right.$ versus $t,\left(t / q_{t}\right)$ versus $t$ and $q_{t}$ versus $\left.t^{1 / 2}\right)$ are presented in Fig. 6. To quantify the applicability of each model, the correlation coefficient $R^{2}$ was calculated from these plots. Comparison of the correlation coefficients $R^{2}$ shows that the pseudo-second-order model fits better the experimental data $\left(R^{2}>0.943\right.$ for hydrochar-ABR and $R^{2}>0.993$ for hydrochar-PE-ABR) than the pseudo-first-order model $\left(R^{2}\right.$ is in the range of $\left.0.735-0.982\right)$ (Table 3). The better fit with pseudo-second-order model

Table 3 Comparison of rate constants calculated based on respective pseudo-first order, pseudo-second order and intra-particle diffusion kinetic models (hydrochar-ABR and hydrochar-PE-ABR dosage $=4 \mathrm{~g} \mathrm{~L}^{-1}$; stirring speed $=200 \mathrm{rpm}$ )

\begin{tabular}{|c|c|c|c|c|c|c|c|c|c|c|}
\hline \multirow[b]{3}{*}{ Samples } & \multicolumn{10}{|l|}{ Parameters } \\
\hline & \multicolumn{4}{|c|}{ First-order kinetics } & \multicolumn{3}{|c|}{ Second-order kinetics } & \multicolumn{3}{|c|}{ Intra-particle diffusion kinetics } \\
\hline & $\begin{array}{l}\text { Initial Conc. } \\
\left(\mathrm{mg} \mathrm{L}^{-1}\right)\end{array}$ & $\begin{array}{l}k_{1} \\
(1 / \min )\end{array}$ & $\begin{array}{l}q_{\mathrm{e}} \\
\left(\mathrm{mg} \mathrm{g}^{-1}\right)\end{array}$ & $R^{2}$ & $\begin{array}{l}k_{2} \\
\left(\mathrm{~g} \mathrm{mg}^{-1} \min ^{-1}\right)\end{array}$ & $\begin{array}{l}q_{\mathrm{e}} \\
\left(\mathrm{mg} \mathrm{g}^{-1}\right)\end{array}$ & $R^{2}$ & $\begin{array}{l}K_{\mathrm{w}} \\
\left(\mathrm{mg} \mathrm{g}^{-1} \min ^{-1 / 2}\right)\end{array}$ & $\begin{array}{l}C \\
\left(\mathrm{mg} \mathrm{g}^{-1}\right)\end{array}$ & $R^{2}$ \\
\hline \multirow[t]{3}{*}{ Hydrochar-ABR } & 50 & 0.0047 & 5.73 & 0.735 & 0.0029 & 5.938 & 0.993 & 0.181 & 1.744 & 0.884 \\
\hline & 75 & 0.0050 & 8.86 & 0.858 & 0.0012 & 8.861 & 0.978 & 0.292 & 1.504 & 0.939 \\
\hline & 100 & 0.0045 & 11.26 & 0.910 & 0.0006 & 9.127 & 0.943 & 0.380 & 1.381 & 0.841 \\
\hline \multirow{3}{*}{ Hydrochar-PE-ABR } & 50 & 0.0094 & 6.84 & 0.982 & 0.0014 & 11.799 & 0.996 & 0.341 & 3.648 & 0.964 \\
\hline & 75 & 0.0077 & 11.15 & 0.972 & 0.0008 & 17.117 & 0.993 & 0.532 & 4.150 & 0.965 \\
\hline & 100 & 0.0062 & 14.55 & 0.935 & 0.0006 & 20.517 & 0.996 & 0.663 & 4.479 & 0.941 \\
\hline
\end{tabular}


Table 4 Comparison of adsorption capacities of various adsorbents used for MG removal

\begin{tabular}{|c|c|c|c|}
\hline Adsorbent & Temperature $\left({ }^{\circ} \mathrm{C}\right)$ & Adsorption capacity $\left(\mathrm{mg} \mathrm{g}^{-1}\right)$ & References \\
\hline Rice husk biochar & 35 & 67.6 & 27 \\
\hline Hydrothermal carbonization of pine needles (HTC-PN) & 25 & 52.91 & 6 \\
\hline Rambutan peel based activated carbon (RPAC) & 30 & 329.49 & 25 \\
\hline Activated carbon laboratory grade & 30 & 42.18 & 38 \\
\hline Activated carbon derived from Borassus aethiopum flower & 30 & 48.48 & 29 \\
\hline Activated carbon prepared from the epicarp of Ricinus communis & 27 & 27.78 & 39 \\
\hline Biochars produced by liquefaction of sewage sludge & 30 & 49.3 & 35 \\
\hline Pine wood decayed by brown-rot fungi (BRW) & 30 & 42.63 & 36 \\
\hline Hydrochar-ABR & 25 & 43.11 & This study \\
\hline Hydrochar-PE-ABR & 25 & 89.05 & This study \\
\hline
\end{tabular}

implies the adsorption process is interaction controlled with chemisorptions involved. But at the same time, the initial rapid phase within the first 480 minutes may involve physical adsorption or ion exchange at hydrochar surface. Therefore, there are at least two mechanisms involved in the actual process. Similar results have been observed in the adsorption of malachite green onto palm flower based activated carbon. ${ }^{29}$ Contribution of intra-particle diffusion mechanism can be tested by applying the Weber and Morris equation as described earlier. It is clear that the relationships between hydrochars and MG for different concentrations at a particular adsorbent do not fit well and do not pass through the origin (Fig. 6). The correlation coefficients $R^{2}$ of the hydrochar derived from PE-ABR is higher than that of the hydrochar-ABR, which indicates that intra-particle diffusion is favorable for PE-ABR-hydrochar and more than one process affects the adsorption of MG by the hydrochars. The slope of the initial linear portion has been used to derive the intra-particle rate constant $K_{\mathrm{w}} \cdot{ }^{36}$ The various values of $K_{\mathrm{w}}$ along with the values of $C$ are shown in Table 3. The rate constant for intra-particle diffusion of PE-ABR-hydrochar increases with increase of MG concentration which indicates an increasing boundary layer effect.

Comparison with other adsorbents. The maximum uptake capacities of the hydrochars derived from ABR and PE-ABR towards MG together with those of other hydrochars, biochars or other carbonaceous materials reported in the literature are listed in Table 4 . The data suggest that the maximum adsorption capacity obtained in the present study is higher than most of other carbonaceous materials. Our previous work using pine wood after decayed by brown-rot fungi for removal rate of MG showed the maximum adsorption capacity reach to $42.63 \mathrm{mg}$ $\mathrm{g}^{-1},{ }^{36}$ was also less than that of the present work result. To increase oxygen-containing surface functional groups of hydrochar, particularly carboxylic group, hydrogen peroxide could be used to oxidize carbonized surfaces of hydrochar from pine needles to increase the adsorption capacity of MG (increased from $52.91 \mathrm{mg} \mathrm{g}^{-1}$ to $97.08 \mathrm{mg} \mathrm{g}^{-1}$ ). ${ }^{6}$ In present study, owing to the algal cell rupture or deformation during the extraction process of phycocyanin, the hydrochar-PE-ABR has richer structure and surface functional groups compared to the hydrochar-ABR, we achieved therefore increased the maximum adsorption capacity.

\section{Conclusions}

This work presents a novel approach that makes better use of phycocyanin-extracted algal bloom residue by converting it to hydrochars through hydrothermal carbonization. The PE-ABRhydrochar shows the maximum adsorption capacity of $89.05 \mathrm{mg}$ $\mathrm{g}^{-1}$ for initial MG concentration of $100 \mathrm{mg} \mathrm{L}^{-1}$ and hydrochars dosages of $4 \mathrm{~g} \mathrm{~L}^{-1}$, much higher than that of ABR-hydrochar (43.11 $\mathrm{mg} \mathrm{g}^{-1}$ ). The mechanism of the MG adsorption is ascribing to the interactions between the various functional groups of the hydrochar interacting with MG. Therefore, we have claimed a more effective and economic way to deal with the waste microalgae biomass from blooms.

\section{Acknowledgements}

This work was supported partly by the Natural Science Foundation of China (No. 11635013, No. 21207137 and No. 11475217), and the National Basic Research Program of China (Grant No. 2014CB932002, No. 2013CB934304).

\section{References}

1 D. Das and A. Pal, Chem. Eng. J., 2016, 290, 371-380.

2 A. Salima, B. Benaouda, B. Noureddine and L. Duclaux, Water Res., 2013, 47, 3375-3388.

3 L. Ai, H. Huang, Z. Chen, X. Wei and J. Jiang, Chem. Eng. J., 2010, 156, 243-249.

4 T. Bhagavathi Pushpa, J. Vijayaraghavan, S. J. Sardhar Basha, V. Sekaran, K. Vijayaraghavan and J. Jegan, Ecotoxicol. Environ. Saf., 2015, 118, 177-182.

5 J.-X. Dong, C. Xu, H. Wang, Z.-L. Xiao, S. J. Gee, Z.-F. Li, F. Wang, W.-J. Wu, Y.-D. Shen, J.-Y. Yang, Y.-M. Sun and B. D. Hammock, J. Agric. Food Chem., 2014, 62, 8752-8758.

6 H. H. Hammud, A. Shmait and N. Hourani, RSC Adv., 2015, 5, 7909-7920.

7 H. Zhang, Y. Tang, D. Cai, X. Liu, X. Wang, Q. Huang and Z. Yu, J. Hazard. Mater., 2010, 181, 801-808.

8 J. A. Libra, K. S. Ro, C. Kammann, A. Funke, N. D. Berge, Y. Neubauer, M.-M. Titirici, C. Fühner, O. Bens, J. Kern and K.-H. Emmerich, Biofuels, 2011, 2, 71-106. 
9 S. M. Heilmann, H. T. Davis, L. R. Jader, P. A. Lefebvre, M. J. Sadowsky, F. J. Schendel, M. G. von Keitz and K. J. Valentas, Biomass Bioenergy, 2010, 34, 875-882.

10 X.-Z. Yuan, X.-S. Shi, C.-X. Yuan, Y.-P. Wang, Y.-L. Qiu, R.-B. Guo and L.-S. Wang, Water Res., 2014, 49, 113-123.

11 M. D. Marsolek, E. Kendall, P. L. Thompson and T. R. Shuman, Bioresour. Technol., 2014, 151, 373-377.

12 W. Zhong, L. Chi, Y. Luo, Z. Zhang, Z. Zhang and W.-M. Wu, Bioresour. Technol., 2013, 134, 264-270.

13 B. Maddi, S. Viamajala and S. Varanasi, Bioresour. Technol., 2011, 102, 11018-11026.

14 Z. Hu, Y. Zheng, F. Yan, B. Xiao and S. Liu, Energy, 2013, 52, 119-125.

15 X. Meng, P. E. Savage and D. Deng, Environ. Sci. Technol., 2015, 49, 12543-12550.

16 M. P. Padgett and D. W. Krogmann, Photosynth. Res., 1987, 11, 225-235.

17 F. Zhang, B. Zhao, J. Cai, M. Yuan, J. Sheng and J. Wang, J. Environ. Eng. Technol, 2015, 5, 499-503.

18 F. Deniz and R. A. Kepekci, Desalin. Water Treat., 2015, 57, 12257-12263.

19 L. Zhang, Q. Wang, B. Wang, G. Yang, L. A. Lucia and J. Chen, Energy Fuels, 2015, 29, 872-876.

20 B. Weiner, J. Poerschmann, H. Wedwitschka, R. Koehler and F.-D. Kopinke, ACS Sustainable Chem. Eng., 2014, 2, 21652171.

21 A. Broch, U. Jena, S. K. Hoekman and J. Langford, Energies, 2013, 7, 62-79.

22 N. D. Berge, K. S. Ro, J. Mao, J. R. V. Flora, M. A. Chappell and S. Bae, Environ. Sci. Technol., 2011, 45, 5696-5703.

23 X. Zhu, Y. Liu, F. Qian, S. Zhang and J. Chen, Energy Fuels, 2015, 29, 5222-5230.
24 T. L. Silva, A. Ronix, O. Pezoti, L. S. Souza, P. K. T. Leandro, K. C. Bedin, K. K. Beltrame, A. L. Cazetta and V. C. Almeida, Chem. Eng. J., 2016, 303, 467-476.

25 M. A. Ahmad and R. Alrozi, Chem. Eng. J., 2011, 171, 510-516.

26 G. K. Parshetti, S. Chowdhury and R. Balasubramanian, Bioresour. Technol., 2014, 161, 310-319.

27 L. Leng, X. Yuan, G. Zeng, J. Shao, X. Chen, Z. Wu, H. Wang and X. Peng, Fuel, 2015, 155, 77-85.

28 B. H. Hameed and M. I. El-Khaiary, J. Hazard. Mater., 2008, 159, 574-579.

29 S. Nethaji, A. Sivasamy, G. Thennarasu and S. Saravanan, J. Hazard. Mater., 2010, 181, 271-280.

30 J. Petrović, N. Perišić, J. D. Maksimović, V. Maksimović, M. Kragović, M. Stojanović, M. Laušević and M. Mihajlović, J. Anal. Appl. Pyrolysis, 2016, 118, 267-277.

31 G. Bekiaris, C. Peltre, L. S. Jensen and S. Bruun, Spectrochim. Acta, Part A, 2016, 168, 29-36.

32 J. H. Yuan, R. K. Xu and H. Zhang, Bioresour. Technol., 2011, 102, 3488-3497.

33 C.-W. Huang, S.-C. Chiu, W.-H. Lin and Y.-Y. Li, J. Phys. Chem. C, 2008, 112, 926-931.

34 F. Lian, G. Cui, Z. Liu, L. Duo, G. Zhang and B. Xing, J. Environ. Manage., 2016, 176, 61-68.

35 L. Leng, X. Yuan, H. Huang, J. Shao, H. Wang, X. Chen and G. Zeng, Appl. Surf. Sci., 2015, 346, 223-231.

36 H. Zhang, Y. Tang, X. Liu, Z. Ke, X. Su, D. Cai, X. Wang, Y. Liu, Q. Huang and Z. Yu, Desalination, 2011, 274, 97-104.

37 D. K. Mahmoud, M. A. M. Salleh, W. A. W. A. Karim, A. Idris and Z. Z. Abidin, Chem. Eng. J., 2012, 181-182, 449-457.

38 I. D. Mall, V. C. Srivastava, N. K. Agarwal and I. M. Mishra, Colloids Surf., A, 2005, 264, 17-28.

39 T. Santhi, S. Manonmani and T. Smitha, J. Hazard. Mater., 2010, 179, 178-186. 